\title{
Proteomic profiling of glucocorticoid-exposed myogenic cells: Time series assessment of protein translocation and transcription of inactive mRNAs
}

\author{
Erica KM Reeves, Heather Gordish-Dressman, Eric P Hoffman* and \\ Yetrib Hathout
}

Address: Research Center for Genetic Medicine, Children's National Medical Center, 111 Michigan Ave NW, Washington DC. 20010, USA

Email: Erica KM Reeves - ereeves@cnmcresearch.org; Heather Gordish-Dressman - hgordish@cnmcresearch.org;

Eric P Hoffman* - ehoffman@cnmcresearch.org; Yetrib Hathout - yhathout@cnmcresearch.org

* Corresponding author

Published: 30 July 2009

Proteome Science 2009, 7:26 doi:10.1 186/1477-5956-7-26

This article is available from: http://www.proteomesci.com/content/7/I/26

(C) 2009 Reeves et al; licensee BioMed Central Ltd.

This is an Open Access article distributed under the terms of the Creative Commons Attribution License (http://creativecommons.org/licenses/by/2.0), which permits unrestricted use, distribution, and reproduction in any medium, provided the original work is properly cited.
Received: 10 March 2009

Accepted: 30 July 2009

\begin{abstract}
Background: Prednisone, one of the most highly prescribed drugs, has well characterized effects on gene transcription mediated by the glucocorticoid receptor. These effects are typically occurring on the scale of hours. Prednisone also has a number of non-transcriptional effects (occurring on minutes scale) on protein signaling, yet these are less well studied. We sought to expand the understanding of acute effects of prednisone action on cell signaling using a combination of SILAC strategy and subcellular fractionations from $\mathrm{C}_{2} \mathrm{C}_{12}$ myotubes.

Results: De novo translation of proteins was inhibited in both SILAC labeled and unlabeled $\mathrm{C}_{2} \mathrm{C}_{12}$ myotubes. Unlabeled cells were exposed to prednisone while SILAC labeled cells remained untreated. After $0,5,15$, and 30 minutes of prednisone exposure, labeled and unlabeled cells were mixed at I:I ratios and fractionated into cytosolic and nuclear fractions. A total of 534 proteins in the cytosol and 626 proteins in the nucleus were identified and quantitated, using 3 or more peptides per protein with peptide based probability $\leq 0.00$ I. We identified significant increases (I.7to $3 . \mathrm{I}$ - fold) in cytoplasmic abundance of II ribosomal proteins within 5 minutes of exposure, all of which returned to baseline by $30 \mathrm{~min}$. We hypothesized that these drug-induced acute changes in the subcellular localization of the cell's protein translational machinery could lead to altered translation of quiescent RNAs. To test this, de novo protein synthesis was assayed after 15 minutes of drug exposure. Quantitative fluorography identified 162D gel spots showing rapid changes in translation; five of these were identified by MS/MS (pyruvate kinase, annexin A6 isoform A and isoform B, nasopharyngeal epithelium specific protein I, and isoform 2 of Replication factor $C$ subunit I), and all showed the $5^{\prime}$ terminal oligopyrimidine motifs associated with mRNA sequestration to and from inactive mRNA pools.
\end{abstract}

Conclusion: We describe novel approaches of subcellular proteomic profiling and assessment of acute changes on a minute-based time scale. These data expand the current knowledge of acute, non-transcriptional activities of glucocorticoids, including changes in protein subcellular localization, altered translation of quiescent RNA pools, and PKC-mediated cytoskeleton remodeling. 


\section{Background}

The synthetic glucocorticoid prednisone is one of the most widely prescribed drugs worldwide due to its potent immunosuppressive and anti-inflammatory effects [1]. Prednisone treatment remains the standard of care for treatment of a variety of disorders including asthma, muscular dystrophy, autoimmune disorders, and arthritis. Other newer and more potent or targeted immunosuppressants have been tried in many of these disorders, but they have been less efficacious than prednisone. However, chronic use of prednisone is associated with significant negative side effects. A greater understanding of prednisone's molecular actions could help optimize treatments that maximize efficacy while minimizing side effects.

The best characterized effect of steroids is their ability to bind soluble steroid hormone receptors, and then move to the nucleus where the receptor complex directly binds to promoter elements and mediates gene transcription. In the case of glucocorticoids, there are well studied glucocorticoid response elements in target gene promoters that are responsible for binding the ligand/receptor complex, with downstream modulation of gene transcription $[2,3]$. Synthetic glucocorticoids have been shown in multiple tissues to decrease membrane fluidity by altering the cholesterol/phospholipids ratio [4-6]. While downstream effects of glucocorticoids on gene transcription and regulation have been well characterized, their non-transcriptional signaling response is poorly understood. Prednisone has been shown to acutely activate protein kinase C (PKC) dependent mitogen activated protein kinase pathway via putative G-protein coupled receptors in immune, brain, and lung cells [7-10]. Additionally, glucocorticoids have been reported to translocate annexin A1 and 5-lipoxygenase and S100A11 to the cytoskeleton in response to glucocorticoid exposure $[8,11,12]$.

We have reported the transcriptional effects of glucocorticoids in muscle cells using in vivo time series data [13]. Methods for profiling proteins are beginning to emerge, and we envisioned that generating proteomic profiling time series data on the minute time scale, integrated with mRNA changes on the minutes time scale, would enable a systems biology understanding of the mechanisms of action of prednisone. Subcellular proteomic profiling to gauge protein translocation on the minute time scale would add important information regarding the effects of prednisone on cell signaling.

To date, protein translocation studies have involved in vivo generation of fluorescent analogs of a target protein followed by its microinjection into live cells [14-16]. The discovery of GFP (and its variants) as an expression reporter in 1997 facilitated the study of protein trafficking
[17]. However, this method has its limitations since only a few proteins can be studied at any given time, and there have been no reports in vertebrate cells of subcellular protein translocation on a more global scale. One form of protein translocation is protein secretion to the extracellular milieu (secretome). Stable isotope labeling by amino acid in cell culture (SILAC) has been successfully applied to study the secretome in a pancreatic cancer cell line [18] and human primary retinal pigment epithelial cells [19].

SILAC strategy has been also used successfully to generate a number of protein profiles, measure kinetics of protein turnover, describe protein-protein interactions, as well as quantitative phosphoproteomics [20-22]. SILAC is one of the most accurate methods for subcellular proteome profiling because labeled and unlabeled cells can be mixed before subcellular fractionation and protein extraction, thus minimizing variation due to experimental handling.

Here, we implemented SILAC strategy to expand our knowledge about intracellular protein translocation in response to pharmacological doses of prednisone. We used an acute time series experiment $(0,5,15$, and 30 minutes) to identify a series of rapid effects of prednisone on protein abundance and subcellular location. These changes were validated by documenting changes in translation of quiescent RNA pools, and cytoplasmic to nuclear translocation of annexin A2. These data provide a potential mechanism underlying the previously reported inhibitory effect of prednisone on cell proliferation.

\section{Results \\ SILAC and subcellular fractionation defines the protein translocation in response to prednisone}

We devised a strategy and experimental method to profile protein translocation in response to prednisone exposure in vitro (Figure 1). The experimental model used was cultured myogenic (muscle) cells $\left(\mathrm{C}_{2} \mathrm{C}_{12}\right.$ myotubes) after exposure to a pharmacological dose of prednisone for 0 , 5,15 , and 30 minutes. To specifically study protein translocation and not de novo changes in protein synthesis, de novo protein synthesis was inhibited with cycloheximide throughout all experiments. The glucocorticoid receptor bound to a ligand (i.e. cortisol, prednisone) is well known to modulate transcriptional activity of target genes, and thus secondarily influence protein abundance and localization. However, both the use of cycloheximide to inhibit translation and short time frames largely rule out de novo transcription as a significant factor in our studies. Most transcription-mediated protein changes occur on the order of hours, while we used minutes of prednisone exposure [13]. Thus, our experimental design should ensure that any changes in protein abundances in our subcellular fraction are not due to alterations in translation 


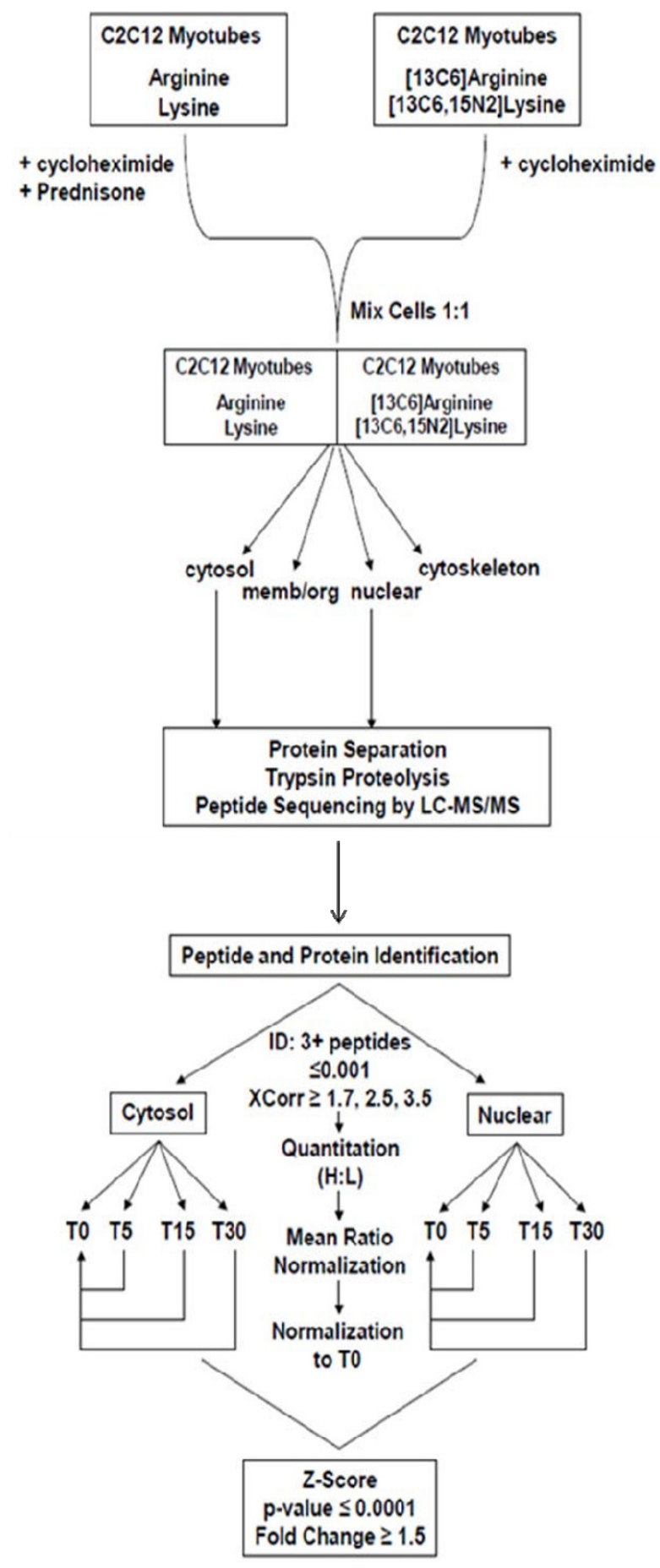

Figure I

Methodology for subcellular proteomic assessment in glucocorticoid-exposed myogenic cells. due to de novo mRNA or protein production known to occur in response to prednisone.

Pairs of steroid-exposed and non-exposed cells from each time point were mixed at $1: 1$ ratio $(\mathrm{w} / \mathrm{w})$, fractionated into cytosolic and nuclear fractions using differential detergent fractionation then processed for proteome profiling as described in the methods section [23]. The number of proteins identified and quantified for each time point and fraction ranged from 316 to 404 for the cytosolic fraction and 318 to 483 for the nuclear fraction. We found small variances for the ratios of multiple peptides mapping to the same parent protein, indicating the accuracy of SILAC strategy. The percentage of overlapping proteins identified across all four time points ranged from $55-71 \%$ and $31-47 \%$ in the cytosolic and nuclear fraction respectively (see Additional file 1 ). The overall identification percentage rate was $41.8 \%$ for the cytosolic fraction and $23.8 \%$ for the nuclear fraction. The nuclear 5 min time point had a higher number of proteins quantified compared to the other time points in both fractions, exemplifying the issue of variability in performing reproducible independent subcellular fractionation.

\section{Prednisone drives acute changes in the cytoskeleton}

We first analyzed the distributions of all protein ratios in each fraction and time point. Figure 2 show the overall ratio distribution of proteins in the cytosolic and nuclear fractions at different time points following exposure to prednisone. The distributions of ratios for T0 (control) were quite narrow (T0 cytosol: $\delta=0.21$ and T0 nuclear: $\delta$ $=0.22$ ). Effects of the drug on protein ratios were statistically significant within 5 and 15 min of prednisone exposure, with broadening of distributions relative to T0 (cytosol T5: $\delta=0.50$ (p-value $<0.0001$; T15 $\delta=0.41(\mathrm{p}-$ value $<0.001)$ respectively and $\delta=0.32(\mathrm{p}$-value $=0.003)$ and $\delta=0.44(\mathrm{p}$-value $<0.001)$ in the nuclear fraction. The distributions at time 30 minutes narrowed considerably, becoming more narrow compared to T0 (cytosol T30 $\delta=$ $0.12(\mathrm{p}$-value $=0.01) ;$ nuclear T30 $\delta=0.14(\mathrm{p}$-value $=$ $0.001)$ ), suggesting that most protein localizations and/or quantities were changed soon after prednisone application, and that these protein changes largely returned to baseline levels by 30 minutes.

We limited analyses to those proteins identified across all time points for a specific fraction, and those proteins with a set ratio and p-value cutoff. Since T0 ratios typically ranged between 0.66 and 1.5, ratios outside this window were considered significant. After filtering, the number of differentially altered proteins was reduced from 223 proteins to 53 proteins in the cytosolic fraction, and from 149 to 16 proteins in the nuclear fraction (see Additional file 2). Many of the most significant temporal changes were seen in cytoskeleton-related proteins (Table 1). In addi- 
T0

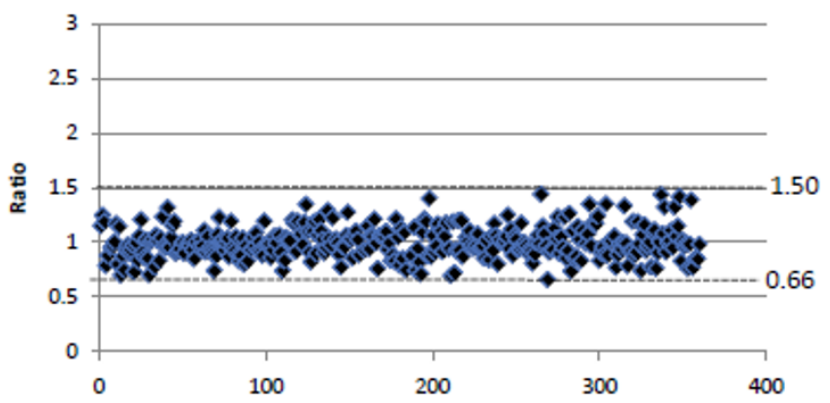

T15

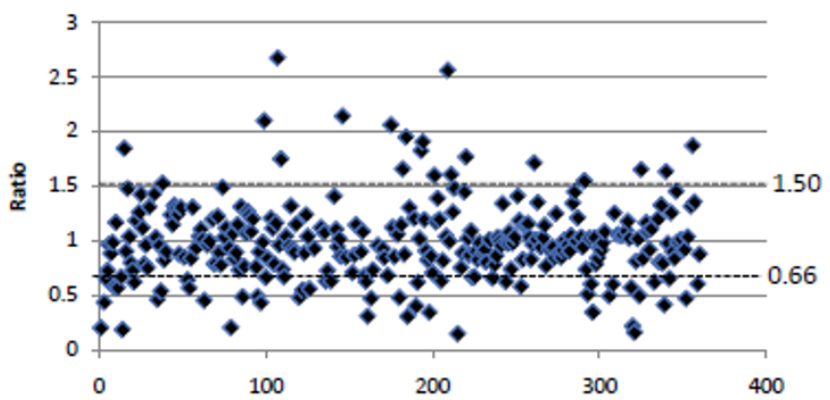

T5

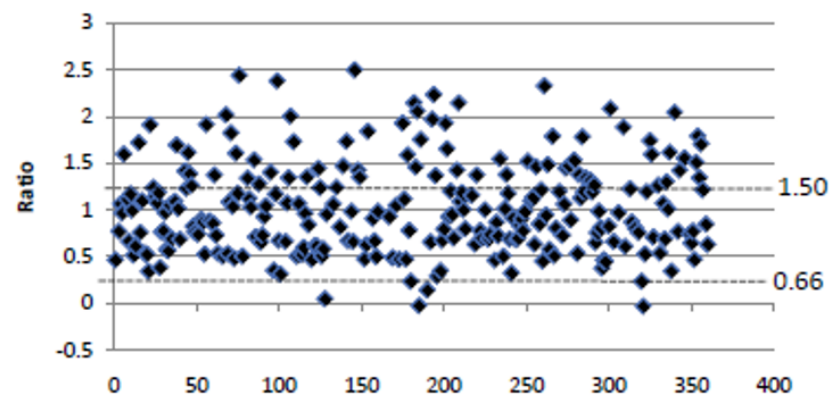

T30

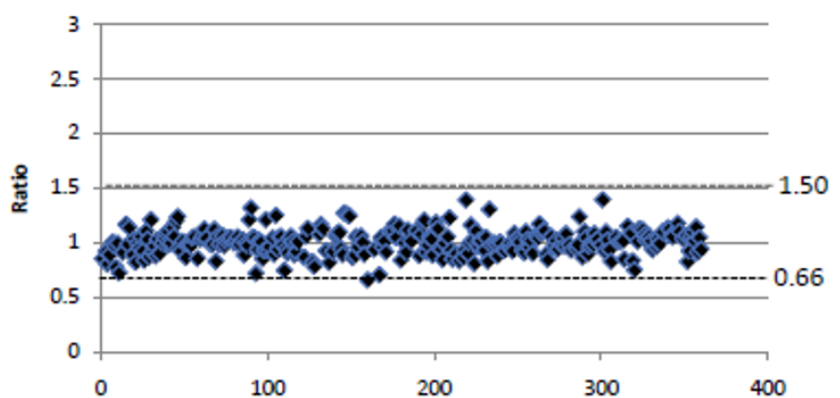

Figure 2

Significant alterations in protein localization within 15 minutes of prednisone Exposure. The overall ratio distributions for cytosolic proteins identified across all time points is shown. Protein ratios outside the range of 0.66 and I.5 were considered significant. Results are derived from a single experiment for each time point. Each sample was comprised of SILAC labeled and unlabeled proteins.

tion to these proteins listed in the table, there was a significant decrease of myosin heavy chain 8 , tropomyosin 1 and troponin $\mathrm{C}$ type 1 in either the cytosol or nucleus for the first 15 minutes of exposure to prednisone. While other cytoskeleton and cytoskeleton-associated proteins such as alpha actinin 4, glutaredoxin 3, myoferlin, talin-1 and vimentin were significantly increased in either the cytosol or nucleus for the first 15 min following prednisone exposure. By $30 \mathrm{~min}$, these proteins (with the exception of tropomyosin 4) had returned to basal levels. This suggests an acute cytoskeleton rearrangement in prednisone-exposed cells versus unexposed cells.

\section{Prednisone rapidly alters subcellular localization of $m R N A$ translational members}

A list of proteins showing significant changes in either the cytosol or nuclear fractions (see Additional file 2) were imported into GO-Getter http://bmf2.colorado.edu/gogetter to obtain gene ontology analysis. The largest percentage $(21.7 \%)$ of proteins from this list was categorized as ribosomal proteins (data not shown). Eleven ribosomal proteins were found to be significantly increased in the cytosolic fraction at 5 min following prednisone exposure (Table 2; Figures 3 and 4). Increased ribosomal proteins included subunits that form the $40 \mathrm{~S}$ and $60 \mathrm{~S}$ ribosomal complex. All of these proteins shared a common transient increase at $5 \mathrm{~min}$ post-prednisone treatment with a return to basal levels by $30 \mathrm{~min}$ posttreatment. In addition to the ribosomal proteins, other proteins involved in transcription/translation also had altered subcellular localization, including elongation factor 1 alpha 1 (EEF1A1), elongation factor 1-alpha 2 (EIF1A2)) and the transcriptional regulators heterogeneous nuclear ribonucleoprotein K (HNRPK), y-box binding protein 1 (YBX1) and proliferation-associated 2G4 (PA2G4) (Figure 4).

The list of proteins used for gene ontology analysis was also imported into Ingenuity Pathway Analysis (IPA). IPA integrates proteomics profiles with a manually-curated database of existing literature. This tool enables the interpretation of data in the context of biological significance. IPA allows statistical ranking of both "canonical pathways" (well-established biochemical pathways) and "net- 
Table I: Top proteins significantly altered in response to prednisone

\begin{tabular}{|c|c|c|c|c|}
\hline Accession & $\begin{array}{l}\text { Fold Change Up-regulated } \\
\text { Molecules }\end{array}$ & FC & SD & \# Pep ID \\
\hline IPI0042I 223.2 & Tropomyosin 4 & 5.03 & 0.10 & 10 \\
\hline IPI00229509.I & Plectin-I & 4.07 & 0.13 & 14 \\
\hline IPI00229534.4 & Myristoylated alanine-rich C-protein & 4.00 & 0.03 & 7 \\
\hline IPI00|3II38.9 & Filamin A & 3.37 & 0.07 & 32 \\
\hline IPI00223253.I & Heterogeneous nuclear ribonucleoprotein $\mathrm{K}$ & 3.34 & 0.12 & 9 \\
\hline IPI00380436.I & Alpha-actinin I & 3.10 & 0.12 & 4 \\
\hline IPI00II324I.6 & Ribosomal protein SI9 & 2.67 & 0.13 & 9 \\
\hline IPI00I 24829.4 & Actin-related protein $2 / 3$ complex subunit 3 & 2.56 & 0.28 & 5 \\
\hline IPI00III83I.I & Nascent polypeptide-associated complex subunit alpha, muscle-specific form & 2.11 & 0.13 & 51 \\
\hline \multirow[t]{2}{*}{ IPI00I26II5.I } & Sideroflexin-3 & 2.11 & 0.05 & 6 \\
\hline & $\begin{array}{l}\text { Fold Change Down-regulated } \\
\text { Molecules }\end{array}$ & FC & SD & \# Pep ID \\
\hline IPI00284| 19.6 & Troponin C, skeletal muscle & -4.35 & 0.10 & 13 \\
\hline IPI003 I 2700.3 & Myosin light chain I & -2.78 & 0.06 & 11 \\
\hline IPI00228548.5 & Enolase 3 & -2.77 & 0.32 & 28 \\
\hline IPI00225275.4 & Glycogen phosphorylase, muscle form & -2.76 & 0.10 & 23 \\
\hline IPI003।9994.5 & L-lactate dehydrogenase $\mathrm{A}$ chain & -2.60 & 0.24 & 24 \\
\hline IPI00223757.3 & Aldose reductase & -2.53 & 0.28 & 12 \\
\hline IPI00| $21788 . \mid$ & Peroxiredoxin-I & -2.45 & 0.16 & 12 \\
\hline IPI0022| 402.6 & Fructose-bisphosphate aldolase A & -2.30 & 0.18 & 11 \\
\hline IPI00I233I9.I & Tropomyosin beta chain & -2.27 & 0.23 & 25 \\
\hline IPI00I I0990.I & Dual specificity protein phosphatase 3 & -2.27 & 0.10 & 11 \\
\hline IPI00II9667.I & Elongation factor I-alpha 2 & -2.24 & 0.10 & 8 \\
\hline
\end{tabular}

works" (protein-protein and gene-protein interactions suggested by the literature). Top ranked networks are defined as those showing the greatest number of connections within a 35 protein 'space'. Analysis of the 69 proteins showing significant subcellular translocation in response to prednisone resulted in a single highly ranked network that contained 25 of the 69 proteins imported. This network contained multiple sub-networks centered on proteins including actin, myosin, HNRPK and annexin A2 (ANXA2) (Figure 5). Many of the proteins mentioned above mapped to this network, further supporting the hypothesis that protein synthesis and cytoskeletal remodeling are significantly affected by prednisone treatment.

While SILAC is one of the most accurate protein quantitative methods, we used immunoblotting as a secondary method to validate a subset of our data. ANXA2 was chosen due to its central position in the network shown in Figure 5, as well as the availability of antibody reagents. The cytosolic, nuclear, membrane/organelle, and cytoskeletal fractions pre- and post-exposure with glucocorticoids were probed for ANXA2 (Figure 6). Consistent with the mass spectrometry data, we found a 2.7 -fold increase of ANXA2 in the nucleus, however this did not reach statistical significance by experimental triplicates due to high variance of the immunoblot results $(\mathrm{p}=0.06)$. More importantly, immunoblot analysis of the mem- brane/organelle fraction showed a significant 2.8-fold decrease of ANXA2 $(p=0.02)$ (Figure 6). These data demonstrate that prednisone induces rapid intracellular migration of ANXA2 from the membrane/organelle compartment to the nuclear compartment and also validate the mass spectrometry quantitation findings.

\section{Acute protein stability and translational response to prednisone}

ANXA2, HNRPK and the majority of proteins networked with these two proteins are involved in the regulation of translationally-inactive messenger ribonucleic acids (mRNAs). We hypothesized that perturbations in translational machinery would lead to downstream changes in the translation of inactive mRNA pools. If true, we would expect to see acute changes in the translation of specific mRNAs in response to prednisone over this time frame, possibly involving traffic of mRNAs to or from quiescent RNA pools.

To test if there was a change in pattern of acute mRNA translation, $\mathrm{C}_{2} \mathrm{C}_{12}$ muscle cells were simultaneously exposed to prednisone and ${ }^{35}$ S-Methione/Cysteine for 15 min in the absence of cycloheximide. Transcriptional inhibitors were not used because they have been shown to activate transcription of quiescent pools of mRNAs [24]. Cytosolic proteins were analyzed by $2 \mathrm{D}$ gels, with fluorog- 


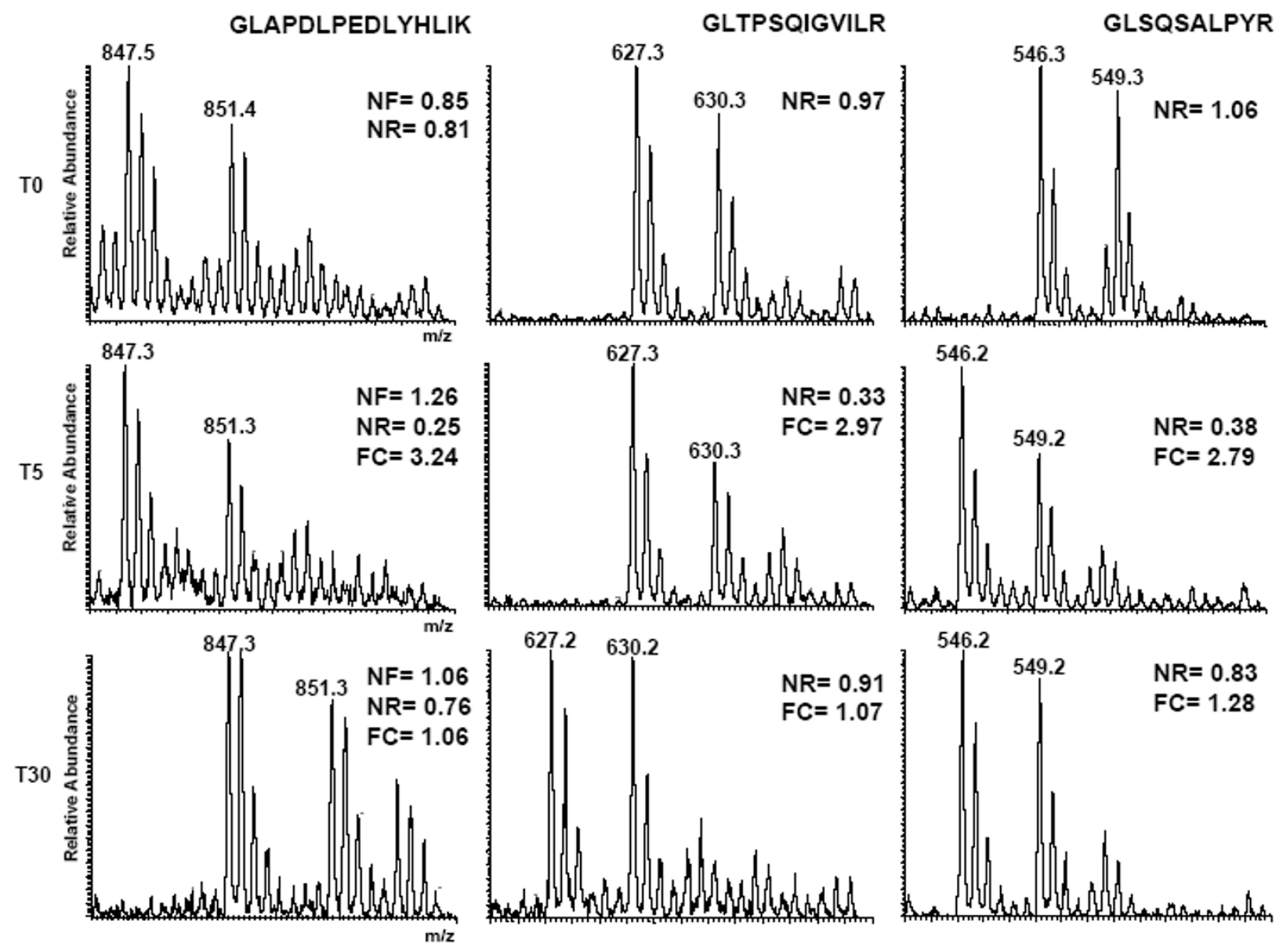

\section{Figure 3}

RPS I 3 increases in the cytosol in response to prednisone. Quantitation of the zoom scans for three unique peptides identified in the cytosolic fraction for RPS I3. The mean ratio for RPS I 3 was multiplied by each timepoint's normalization factor (NF), which was calculated to adjust the overall protein population mean ratio to I.0. Peptides were normalized to their corresponding baseline peptide at T0, resulting in a normalized peptide ratio (NR). The NR was then converted to a fold change (FC). Results showed an increase in RPSI 3 levels detectable through TI5 (I 5 minutes) post-exposure. Quantitation was performed on the intercalating zoom scans for the corresponding MS2 scan by taking the ratio of the monoisotopic peak of the heavy (labeled) peak divided by the monoisotopic peak of the light (unlabeled, prednisone-exposed) peak.

raphy to detect de novo synthesized proteins over the 15 min time frame. All experiments were carried out in biological triplicate, and automated quantitative analyses of autoradiography gels performed by Ludesi.

A total of 832 different spots were detected between the control and prednisone gels. Analysis was limited to spots identified in all gels in both groups $(n=274)$ or those identified in all three gels from a single group (exposed $n$ = 83; unexposed $n=81)(n=438$ non-redundant spots $)$. Fifteen spots had a fold change $\geq 1.5$ and $p$ value $\leq 0.05$ in the exposed group when compared to unexposed controls (Figure 7). These spots were selected for peptide mass fin- gerprint identification using Coomassie stained gels. Eight of the fifteen proteins were abundant enough to be detected on the less sensitive Coomassie stained gel and could be confidently mapped and excised. Of these eight proteins, five proteins showed adequate MS/MS results for unambiguous identification (Table 3).

The 5' untranslated region (UTR) of the genes corresponding to each of the proteins was analyzed for RNA regulatory motifs using the publicly available web server RegRNA http://regrna.mbc.nctu.edu.tw/index.html. Each of the five proteins contained multiple 5 ' terminal oligopyrimidine tracts (TOP) (Table 3 ). Both nasopharyn- 


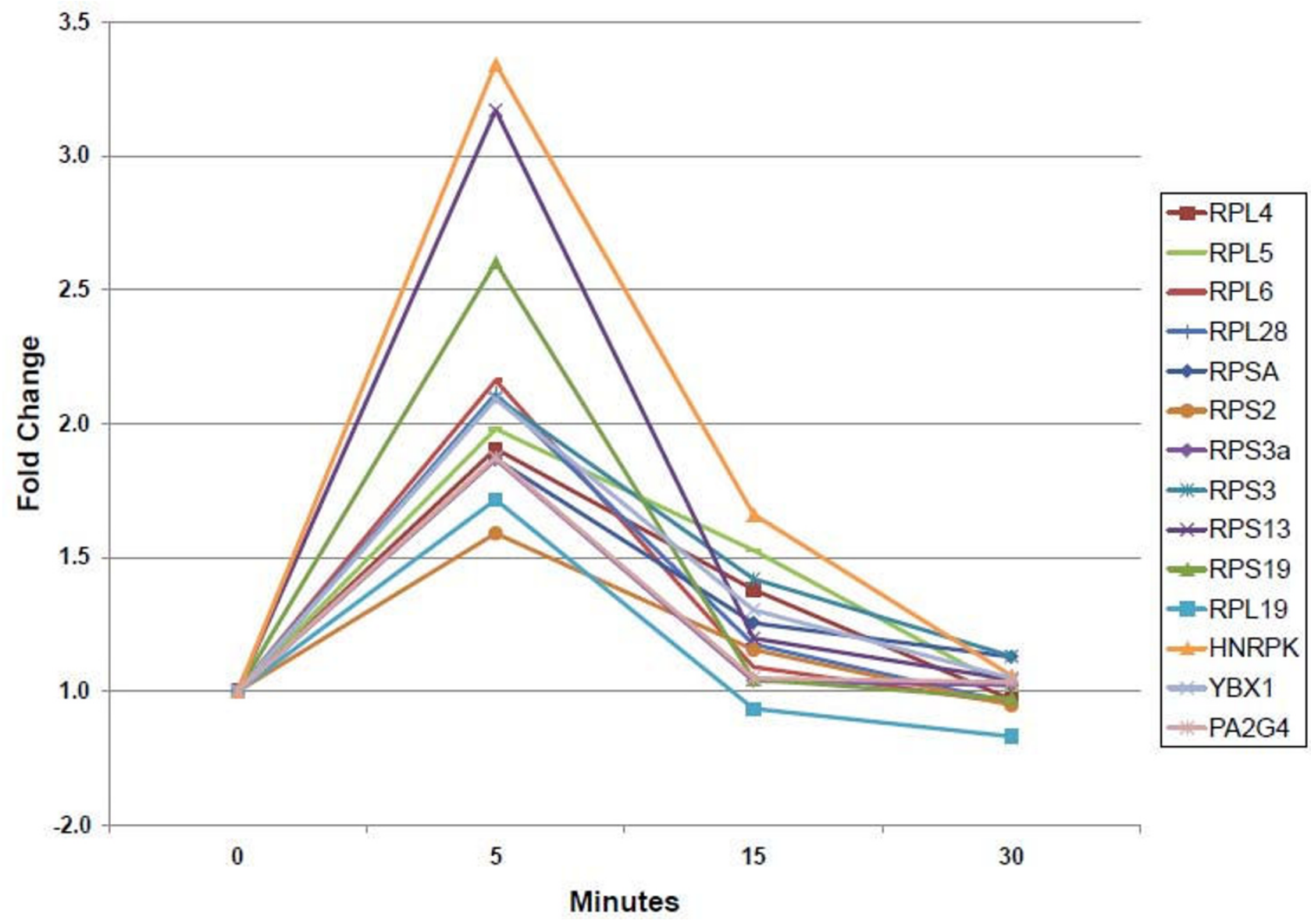

\section{Figure 4}

Temporal profiling of transcriptional/translational proteins showing acute translocation into the cytosol. Shown are relative ratios of ribosomal proteins and transcriptional regulators with significant changes in the cytosol following exposure to prednisone. All proteins reached their maximum levels at five minutes and returned to baseline levels by 30 minutes.

Table 2: Transient increase in ribosomal proteins in the cytosol

\begin{tabular}{|c|c|c|c|c|c|c|c|}
\hline \multirow[b]{2}{*}{ IPI Accession No. } & \multirow[b]{2}{*}{ Protein } & \multicolumn{2}{|l|}{ T5 } & \multicolumn{2}{|l|}{ TI5 } & \multicolumn{2}{|l|}{ T30 } \\
\hline & & FC & $\mathrm{P}$-value & FC & p-value & FC & $\mathrm{p}$-value \\
\hline IPI00III 272.1 & PREDICTED: similar to 40 S ribosomal protein SA & 1.87 & 0.00000 & 1.26 & 0.04298 & 1.13 & 0.226600 \\
\hline IPI00III4I2.2 & $60 S$ ribosomal protein L4 & 1.91 & 0.00000 & 1.38 & 0.00169 & 0.97 & 0.510430 \\
\hline IPI00II $324 \mid .6$ & $40 \mathrm{~S}$ ribosomal protein $\mathrm{SI} 9$ & 2.60 & 0.00000 & 1.04 & 0.32051 & 0.97 & 0.885180 \\
\hline IPI00I 25901.4 & $40 \mathrm{~S}$ ribosomal protein $\mathrm{SI} 3$ & 3.17 & 0.00000 & 1.20 & 0.60448 & 1.04 & 0.079524 \\
\hline IPI00I34599.I & $40 \mathrm{~S}$ ribosomal protein $\mathrm{S} 3$ & 2.10 & 0.00000 & 1.42 & 0.00167 & 1.13 & 0.439200 \\
\hline IPI00|34607.5 & PREDICTED: similar to 40 S ribosomal protein S2 & 1.59 & 0.00000 & 1.16 & 0.09428 & 0.95 & 0.476900 \\
\hline IPI00222547.5 & 60 S ribosomal protein $\mathrm{L} 28$ & 2.11 & 0.00001 & 1.18 & 0.00304 & 0.96 & 0.816390 \\
\hline IPI00282248.I & PREDICTED: similar to $60 \mathrm{~S}$ ribosomal protein L6 & 2.16 & 0.00000 & 1.09 & 0.61050 & 0.96 & 0.177500 \\
\hline IPI00308706.3 & $60 S$ ribosomal protein $\mathrm{L} 5$ & 1.98 & 0.00000 & 1.53 & 0.44499 & 1.01 & $0.06 \mid 444$ \\
\hline IPI0033I345.4 & 40 S ribosomal protein S3a & 1.87 & 0.00000 & 1.04 & 0.00000 & 1.02 & 0.889755 \\
\hline IPI00I 22426.I & 605 ribosomal protein LI9 & 1.72 & 0.00000 & 0.93 & 0.65748 & 0.83 & 0.321220 \\
\hline
\end{tabular}




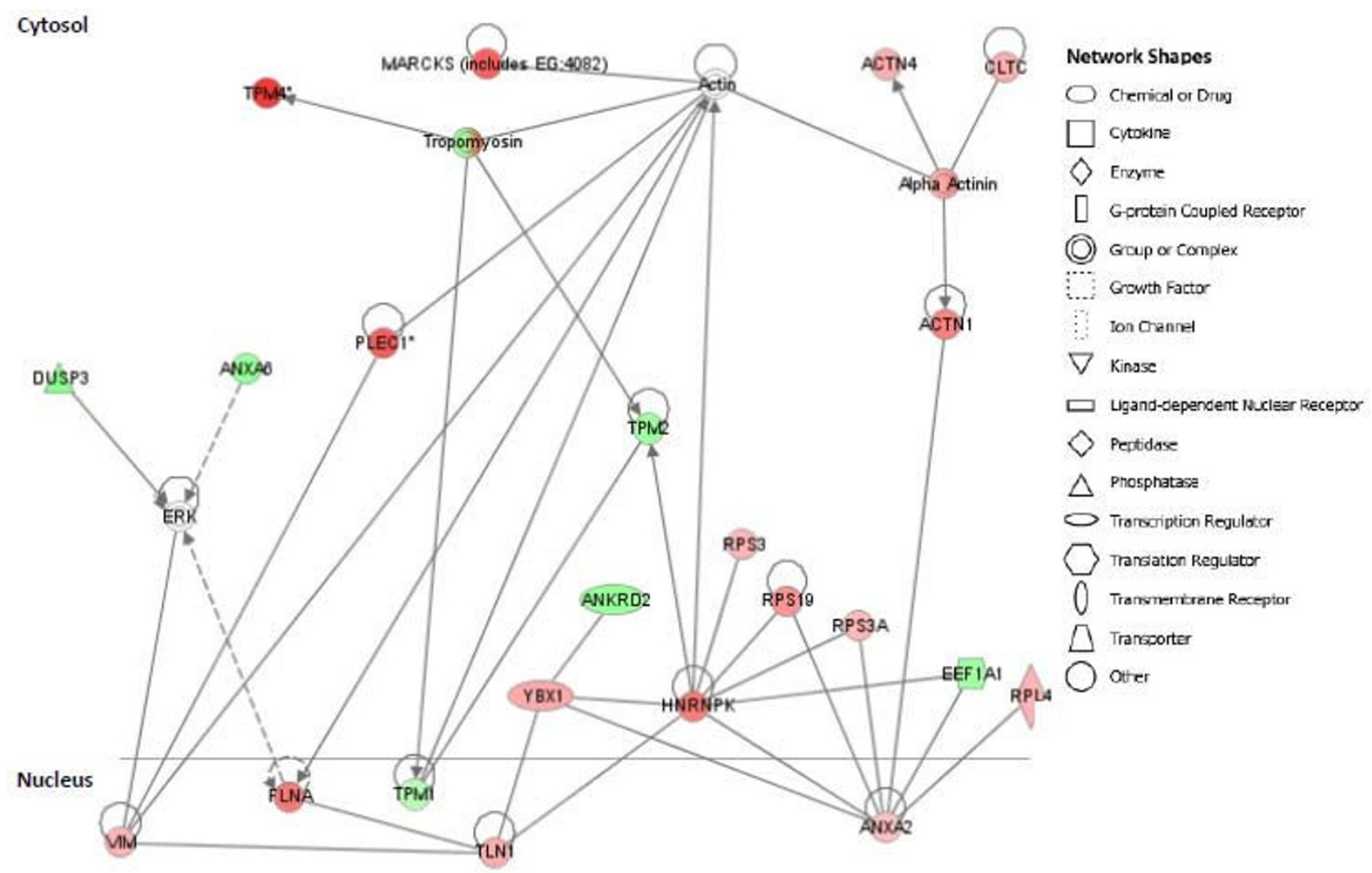

Figure 5

Network analysis of translocated proteins. All proteins $(n=69)$ showing significant translocation in or out of the cytosol or nuclei following prednisone exposure were loaded into Ingenuity Pathway Analysis. This analysis queries published proteinprotein or gene-protein interactions between members of the 69 protein set. Proteins were placed in the subcellular fraction in which they were found to change abundance. Red indicates an increase in that fraction, green a decrease. This network includes a sub-network centered on ANXA2 and is connected with ribosomal proteins and other proteins involved in translational machinery. White color indicates proteins mapped to the network that were part of the imported data. Solid line indicates a direct interaction between molecules. Dashed lines indicate an indirect interaction between molecules.

geal epithelium specific protein 1 (NESG1) and isoform 2 of replication factor $\mathrm{C}$ subunit 1 (RFC1) also contained Gamma interferon activated inhibitor of Ceruloplasmin mRNA translation (GAIT) elements.

\section{Discussion}

We defined acute (minutes of treatment exposure time scale) protein changes in subcellular fractions in response to prednisone with time series data, enabling some delineation of cause/effect of observed changes in protein subcellular localization. Our experimental design involved a SILAC strategy to monitor temporal protein translocation in prednisone-exposed $\mathrm{C}_{2} \mathrm{C}_{12}$ cells (Figure 1). We used stringent criteria for protein identification and quantitation to reduce the number of false positive identifications and to provide an assessment of variance of peptide ratios between time points.

The percentage of proteins identified across all time points (e.g. 0, 5, 15, and 30 min exposure) is low when compared to the total number of identified proteins (41.8\% in the cytosol and $23.8 \%$ in the nucleus) and this is due to the poor reproducibility when dealing with multiple subcellular fractionations (see Additional file 1). However, these percentages are higher than previously reported values. Currently, there are only a handful of published papers using a SILAC-based LC-MS/MS in temporal studies. Additionally, not all of these published papers address protein identification rates across samples and fractions. A recent paper published from our group (focused on the endoplasmic stress response) found 
A

membrane/organelle

nucleus

B

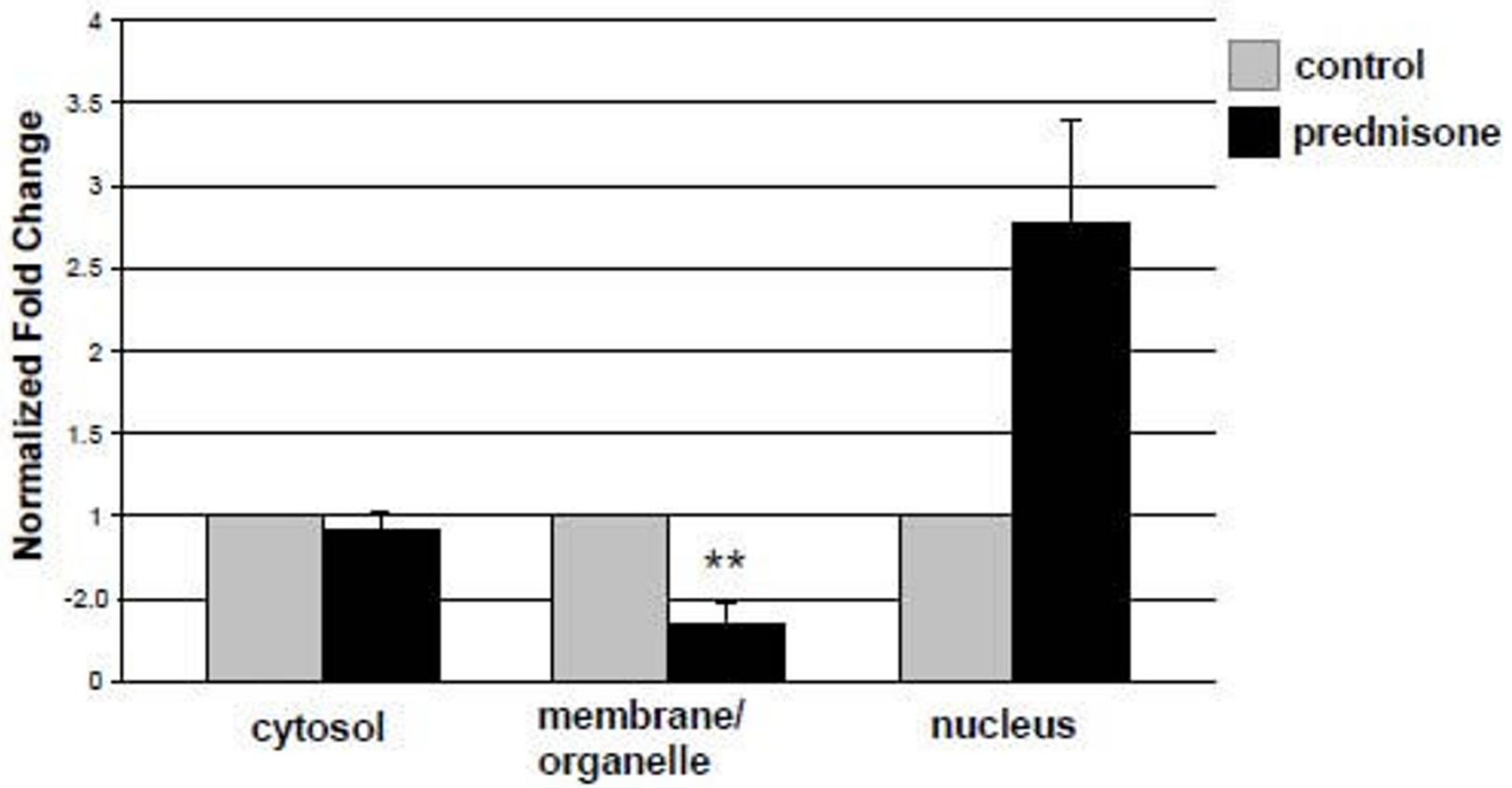

Figure 6

ANXA2 translocates from the membrane/organelle fraction to the nucleus in response to prednisone. Shown is immunoblot analysis of $\mathrm{C} 2 \mathrm{Cl} 2$ subcellular fractions probed for ANXA2 (A), and quantitation of experimental triplicates densitometry (B). ANXA2 was not detected in the cytoskeleton fraction (data not shown). ANXA2 migrated from the membrane/ organelle fraction to the nucleus within 15 minutes of prednisone exposure $(* *=p \leq 0.05)$. Data in Panel $B$ are mean \pm SE. 
(A)

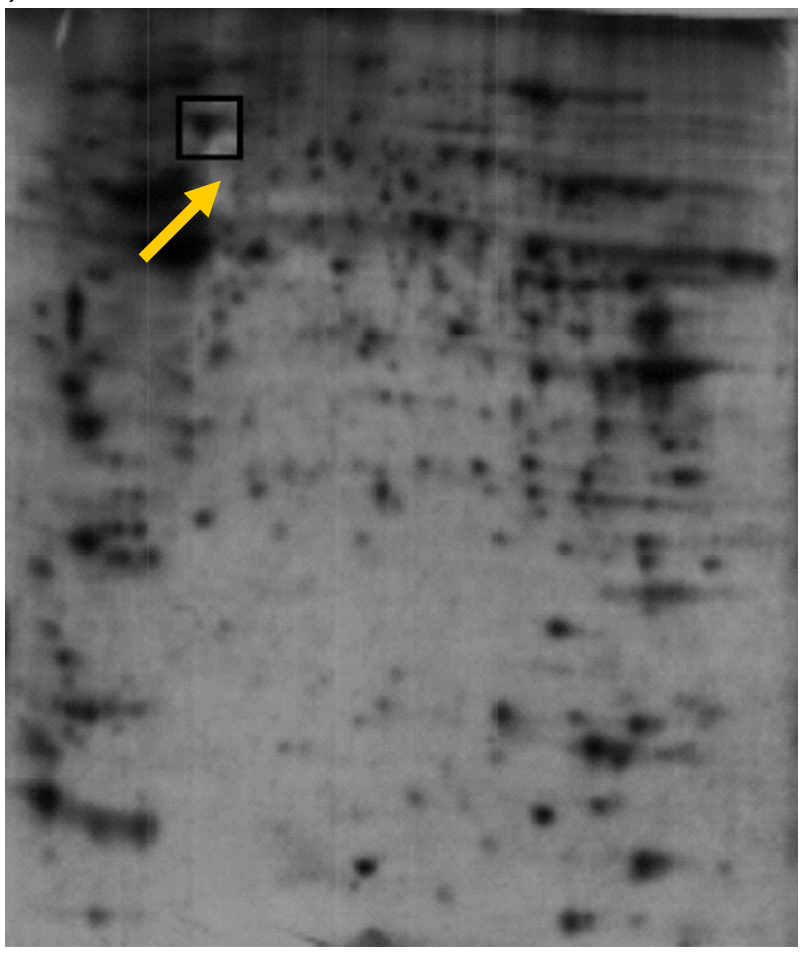

(B)

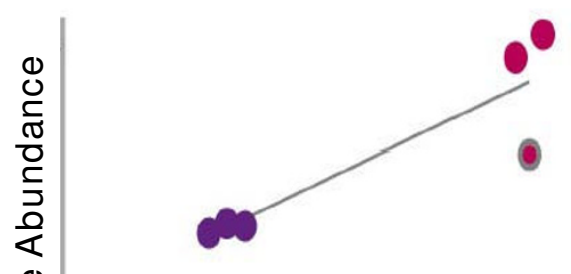

Fold Change $=-2.26$

$p$-value $=0.023$

ฯ

prednisone control

(C)

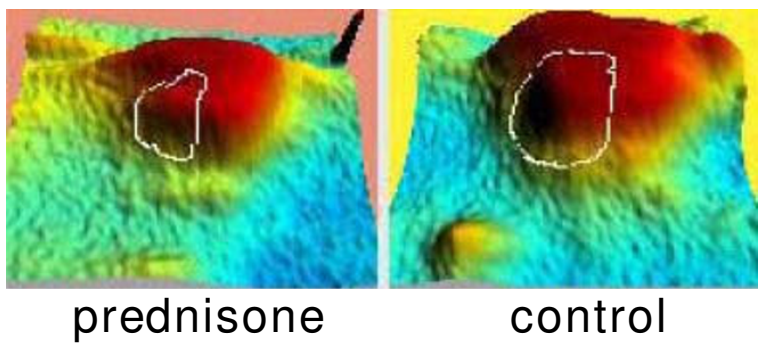

\section{Figure 7}

35S-Methionine/Cysteine labeling of de novo protein translation identifies reduced ANXA6 isoform A protein translation patterns. One of the 5 proteins showing altered translation patterns was Annexin A6 (ANXA6) isoform A which decreased 2.23 in response to prednisone. (A) Original prednisone-exposed autoradiography gel. Arrow points to location of ANXA6.A. (B) Normalized means of relative protein abundance for triplicate experiments. (C) Enlarged view of the resolved ANXA6.A spot of the 3D rendering of the 2D montage.

$19.7 \%$ of total identified proteins overlapping across four time points [25]. Another study (focused on concurrent temporal protein expression patterns during B-cell differentiation) found $23.4 \%$ overlapping proteins across five time points [26]. Our higher percentages could be attributed to more stringent filtering criteria.

Significantly altered proteins between what and what were imported into Ingenuity for network analysis. Many of the molecules in the highest ranked network were cytoskeleton-related proteins (Table 1; Figure 5). These proteins, in addition to the numerous other cytoskeleton proteins found to significantly change localization in response to prednisone, suggest an acute cytoskeleton remodeling of muscle cells in response to prednisone exposure. Glucocorticoid-induced actin remodeling has not been demonstrated in muscle but has been found in other tissues. In keratinocytes, glucocorticoids induced rapid actin assembly in endometrial cells [27,28]. A dosedependent decrease in the $\mathrm{G} /$ total actin ratio was seen

Table 3: Altered de novo translation patterns in response to prednisone

\begin{tabular}{cclccc}
\hline Fold Change & P-value & Protein & Accession \# & C.I & \#TOP motifs \\
\hline I.79 & 0.027 & Pyruvate kinase isozyme M2 & IPI00407|30 & 98.7 & 6 \\
-2.26 & 0.023 & Annexin A6 isoform A & IPI00649I52 & 100 & 6 \\
I.68 & 0.017 & Annexin A6 isoform B & IPI003I0240 & 100 & 6 \\
-3.55 & 0.039 & Nasopharyngeal epithelium specific protein I & IPI00474207 & 100 & 6 \\
Control Only & 0.046 & Isoform 2 of Replication factor C subunit I & IPI00378I68 & 99.8 & 4 \\
\hline
\end{tabular}


with a concurrent increase in F-actin in as early as 15 minutes of exposure.

Numerous studies have implicated the activation of PKC and PKC-mediated cytoskeleton remodeling in response to glucocorticoids in non-muscle tissues [10,29-31]. In the present study, several PKC binding proteins showed alterations in protein localization, including EEF1A, EEF1A2, myristoylated alanine-rich C-protein (MARCKS) and glutaredoxin-3 (GLRX3) in or out of the cytosol. GLRX3 (also known as PICOT) was shown to bind calcium-independent PKC $\theta$. In unstimulated T-cells, GLRX3 is distinctly localized to the cytoplasm. PKC $\theta$ stimulation results in the co-translocation of PKC $\theta$ and GLRX3 to a submembrane location [32]. In cardiac muscle, GLRX3 interacts with muscle LIM protein located at cardiac Zdisks, where it interacts with other Z-disk proteins such as alpha-actinin, zyxin, and T-cap [33]. GLRX3 competitively displaces calcineurin and disrupts dephosphorylation of NFAT and subsequent downstream signaling. GLRX3 may also bind specific PKC isozymes inhibiting downstream MAPK activity. The author suggests that this scaffolding domain functions as an inhibitor of the hypertrophic signal transduction. This model could be applied to the atrophic response of skeletal muscle to glucocorticoids.

Another PKC substrate, MARCKS, decreased in the cytosol. MARCKS is an actin filament cross-linking protein normally localized to focal adhesions at the plasma membrane. Phosphorylation by PKC inhibits its association with actin at the plasma membrane and results in increased cytosolic localization [34]. Glucocorticoid treatment rapidly increased MARCKS 4.2-fold in the cytosol. In muscle, PKC-dependent translocation of MARCKS correlates with integrin signaling and actin cytoskeleton remodeling [35]. MARCKS transcription is downregulated by glucocorticoids [13]. Other integrin signaling proteins, including actin related protein complex subunit 3 and alpha actinin 1 and 4 and numerous cytoskeleton-related proteins, also significantly altered localization further suggesting an acute cytoskeletal remodeling occurring. Taken together, our data suggests there is a potential non-transcriptional PKC-mediated cytoskeletal remodeling occurring within minutes of prednisone exposure. However, further experiments are required to validate this result and delineate which molecular mechanisms are responsible.

In addition to the cytoskeletal and cytoskeleton-bound proteins, there were significant changes seen in proteins involved in protein synthesis. Multiple ribosomal proteins and transcriptional regulators increased in the cytosolic fraction upon glucocorticoid treatment (Table 2; Figures 3 and 4). All of these proteins shared a common temporal pattern, with the greatest increase in the cytosol seen within 5 minutes of prednisone exposure and return- ing to basal levels by 30 minutes (Figures 3 and 4). We hypothesize that the ribosomal proteins are translocating into the cytosolic fraction from either the cytoskeleton or the membrane/organelle fraction. An alternative interpretation is that these proteins may be stabilized by drug treatment. Unfortunately, antibody reagents are not currently available to test these models. We were able to validate the ANXA2 mass spectrometry findings using immunoblot, and by testing additional fractions showed that the intracellular movement was likely translocating from the membrane/organelle to the nuclear compartment (Figure 6). ANXA2 has been observed in multiple subcellular compartments and is known to traffic between the cytosol and nucleus [36]. Nuclear retention of ANXA2 results in reduced cell proliferation in prostrate cells [37]. Extrapolating from these data, the steroid-induced migration of ANXA2 from the membrane/organelles to the nucleus may be, at least in part, responsible for the reduced $\mathrm{C}_{2} \mathrm{C}_{12}$ proliferation observed in response to glucocorticoids [38]. This is the first report that we are aware of demonstrating glucocorticoid-induced alteration of ANXA2 localization in skeletal muscle.

Glucocorticoids have a receptor-mediated transcriptional response that alters transcriptional profiles. This is the first report demonstrating that ribosomal proteins and transcriptional regulators (i.e. ANXA2, HNRPK, YBX1, etc) have a non-transcriptional mechanism of action. We hypothesized that the observed rapid increase of ribosomal proteins into the cytosol by 5 minutes of steroid treatment could lead to acute changes in mRNA translation patterns, perhaps via sequestering of mRNAs to or from inactive mRNA pools. To test this, we exposed $\mathrm{C}_{2} \mathrm{C}_{12}$ myotubes with ${ }^{35} \mathrm{~S}$-Methione/Cysteine and prednisone for 15 minutes to label all de novo protein translation products rapidly induced by drug treatment. Fifteen spots showed a fold change $\geq 1.5$ and p-value $\leq 0.05$ and, of these 15 , five were abundant enough to identify by LCMS/MS (Table 3; Figure 7).

If these five proteins were translated from quiescent RNA pools, then the corresponding 5' UTR of the mRNAs would be expected to contain TOP motifs commonly associated with components of these inactive mRNA pools [39]. All five proteins showing drug-induced acute translation showed multiple TOP motifs in the 5'UTR of their corresponding mRNAs. $6.6 \%$ of all mRNAs show $\geq 1$ TOP motif(s) [40], and our finding of 5/5 showing multiple TOP motifs was compelling (probability of 1 in $1.2 \times$ $10^{-6}$ ). Our data suggests that prednisone is sequestering mRNAs to or from the inactive mRNA pools, leading to a rapid shift in ribosomal proteins to the cytosol. This response appears short-lived, with re-equilibration of the protein translocation pattern within 30 minutes of treat- 
ment. However, de novo protein translation would be expected to show a more sustained effect.

Translation of TOP mRNAs is dependent upon the growth status of the cell. In growing cells, TOP mRNAs are localized at polysomes and are actively transcribed whereas in quiescent cells, TOP mRNAs are localized at small polysomes and translationally-inactive messenger ribonucleoproteins, where they can be stored for up to a week [41]. Many of the proteins involved in proteins synthesis are represented in the ANXA2-centered sub-network (Figure 5) described above, and are involved in translation of inactive mRNAs. ANXA2 and PA2G4 are both RNA-binding proteins that are present in pre-ribosomal ribonucleoprotein complexes $[42,43]$.

Three of the de novo-translated proteins showed an increase in translation, while two showed a significantly decreased rate. The two negatively regulated proteins (NESG1 and RFC1) contain GAIT elements in their 5' UTR. A GAIT element is a cis-acting RNA element involved in selective translational silencing of ceruloplasmin by interferon gamma-activated inhibitor of translation [44]. It has been suggested that the translational silencing of ceruloplasmin and other GAIT-containing transcripts may aid in resolving the local inflammatory response. It is possible that decreases of translation observed in NESG1 and isoform 2 of RFC1 could be attributed to translation silencing via this same mechanism. Overall, it seems that 5 'TOP motifs are involved in the acute non-translational response of myotubes to prednisone, with additional motifs controlling whether a shift from or to the quiescent mRNA pools is observed.

\section{Conclusion}

In summary, we describe a systematic approach for monitoring intracellular protein translocation using SILAC and apply this to the acute non-transcriptional response of myogenic cells to prednisone. We found an acute translocation of many cytoskeleton and cytoskeleton-bound proteins indicative of rapid remodeling. Additionally, we discovered the translocation of ribosomal proteins into the cytosol, which was commensurate with de novo translation patterns in a subset of mRNAs. These mRNAs were translated within 15 minutes of exposure, and showed features consistent with transport in or out of quiescent pools. The translocation of ribosomal proteins rapidly returned to baseline by 30 minutes, while the de novo translation patterns likely have a more persistent druginduced effect.

\section{Methods}

\section{Tissue culture methods}

Mouse $\mathrm{C}_{2} \mathrm{C}_{12}$ myoblasts were grown in DMEM supplemented with $10 \%$ FBS and 1\% Penicillin/Streptomycin.
Concurrently, equal amounts of mouse $\mathrm{C}_{2} \mathrm{C}_{12}$ cells were incubated in custom-made DMEM medium depleted of Arg and Lys and supplemented with ${ }^{13} \mathrm{C}_{6}$-Arg (147.5 ug/ $\mathrm{mL})$ and ${ }^{13} \mathrm{C}_{6},{ }^{15} \mathrm{~N}_{2}$-Lys (91.25 ug/mL), as well as $10 \% \mathrm{FBS}$ and $100 \mathrm{U} / \mathrm{mL}$ each of penicillin/streptomycin. The presence of $10 \%$ whole serum in the culture medium does not interfere with the incorporation of the exogenous stable isotope labeled amino acids and can be used in place of dialyzed FBS serum [45]. All cells were sub-cultured for five passages to allow full incorporation of isotopes into the cells grown in labeled medium. At five passages, full isotope incorporation was achieved. All cells were serumstarved into differentiation using DMEM supplemented with 2\% horse serum and 1\% Penicillin/Streptomycin.

\section{Steroid exposure and subcellular fractionation}

On day five of differentiation, both SILAC labeled and non-labeled cells were exposed for $1 \mathrm{hr}$ to $35 \mu \mathrm{M}$ cycloheximide to arrest translation prior to steroid treatment. Unlabeled myotubes were exposed to $1 \mu \mathrm{M}$ of Prednisone for 5, 15, or 30 minutes while SILAC labeled cells were unexposed. At each time point steroid-exposed cells were mixed, at $1: 1$ ratio $(\mathrm{w} / \mathrm{w})$, with the non-exposed SILAC labeled cells fractionated using the differential detergent extraction method [23]. Mixing samples prior to fractionation controls for differences in experimental handling. For a control, labeled and unlabeled cells at the 0 minute time point were exposed with cycloheximide but not prednisone. Cytosolic and nuclear fractions were processed for LC-MS/MS analysis.

\section{Peptide extraction}

$100 \mu \mathrm{g}$ of total protein for each fraction and time point was desalted and dry vacuumed to completion, brought up in $30 \mathrm{uL}$ Laemmle buffer containing $50 \mathrm{mM}$ DTT, and incubated for $30 \mathrm{~min}$ at room temperature. 1D protein separation was performed using a precast $4-12 \%$ SDSPAGE gel, fixed using methanol:water:acetic acid (45:50:5, vol/vol/vol) for $30 \mathrm{~min}$ and stained with Coomassie blue. The fractionated lane was excised into 35 bands. In-gel digestion was performed [46]. Extracted peptides were dissolved in $0.1 \%$ TFA.

\section{LC-MSIMS analysis quantitative and statistical analysis of proteins}

All analyses were carried out on a Thermo LTQ Linear iontrap connected to a nano-LC system. Each sample was injected via an autosampler and loaded onto a C18 trap column $(5 \mu \mathrm{m}, 300 \mu \mathrm{m}$ i.d. $\times 5 \mathrm{~mm})$, for $6 \mathrm{~min}$ at a flow rate of $10 \mu \mathrm{L} / \mathrm{min}, 100 \% \mathrm{~A}$. The sample was subsequently separated by a C18 reverse-phase column $(3.5 \mu \mathrm{m}, 100$ $\mu \mathrm{m} \times 15 \mathrm{~cm})$ at a flow rate of $200 \mathrm{~nL} / \mathrm{min}$. The mobile phases consisted of water with $0.1 \%$ formic acid (A) and $90 \%$ acetonitrile with $0.1 \%$ formic acid (B). A $100 \mathrm{~min}$ linear gradient from 5 to $60 \%$ B was typically employed. 
The LTQ was operated in data-dependent mode in which one cycle of experiments consisted of one full-MS survey and subsequently three sequential pairs of intercalated zoom scans and MS/MS experiments. The targeted ion counts in the ion trap during full-MS, zoom scan, and MS/ MS were 30000, 3000, and 10000, respectively. Peptides were fragmented in the linear ion trap using collisioninduced dissociation with the collision gas (helium) pressure set at 1.3 milliTorrs and the normalized collision energy value set at $35 \%$. The zoom scan events are of higher resolution higher than and were used to determine the charge state of the ion as well as the ratio of labeled to unlabeled peptide pairs.

\section{Data base search and quantitative analysis}

MS/MS spectra files from each LC run were searched using Sequest against the publicly available mouse EMBL-EBI International Protein Index (IPI) database v3.22 with the following variable parameters: oxidized methionine (15.0 Da) and phosphorylation of serine, threonine, and tyrosine $(80.0 \mathrm{Da})$, and [13C6, 15N2]-lysine $(8.0 \mathrm{Da})$ and [13C6]-arginine (6.0 Da) as variable modifications, fully enzymatic trypsin cleavage specificity allowing for two missed cleavages and 0.8 Da for MS/MS ions. Results were filtered using the following criteria: different peptides, delta $\mathrm{CN}=0.1$, XCorr vs. Charge State = 1.9, 2.5, and 3.5 (for singly, double, and triply charged peptides respectively), peptide probability $=0.001$, number of different peptides $=3$. Manual quantitation was performed, where the ratios of at least 3 different peptides were quantitated by dividing the relative abundance of the monoisotopic peak of the heavy peptide by the relative abundance of the monoisotopic peak of the light peptide. Mean and standard deviation of the unexposed/exposed peptide ratios were calculated for each identified protein using all peptides available $(n \geq 3)$. To adjust for any error in the mixing of labeled and unlabeled cells prior to subcellular fractionation, the average ratio obtained for each protein in a given subcellular fraction and at a given time point was normalized to the average median mean value obtained for that data set. Protein ratios in each of the steroid-exposed sets (T5, T15, and T30) were normalized to the control (T0) by subtracting the control mean for a given protein from the steroid-exposed mean of the same protein. This normalized ratio was used to calculate a $\mathrm{z}$ score and corresponding p-value, indicating if each protein in the steroid-exposed condition was significantly different from the unexposed population. Fold changes for all proteins were also calculated. Results are derived from a single experiment for each time point. Each sample is comprised of SILAC labeled and unlabeled proteins.

\section{Immunoblot analysis}

$\mathrm{C}_{2} \mathrm{C}_{12}$ myoblasts were grown and differentiated under conditions described above. Five days post-differentiated, myotubes were exposed to prednisone for 15 minutes and fractionated using the differential detergent fractionation as described above. Positive controls were 30 ug total protein from NIH/3T3 whole cell lysates. 30 ug of total protein from each subcellular fraction was separated under reducing conditions via one dimensional separation on a $10 \%$ SDS-PAGE gel. Proteins were transferred onto a PVDF membrane and blocked in 5\% non-fat dried milk in TBS/0.05\% Tween 20 (TBST) for 1 hour. Membranes were incubated overnight with an ANXA2 specific antibody; Santa Cruz Biotechnology Inc.). After three washes with TBST, membranes were incubated at room temperature for $1 \mathrm{~h}$ using a peroxidase-labeled (HRP) secondary antibody (Santa Cruz) in 5\% non-fat dried milk in TBST. After three washes in TBST, bound antibodies were detected by the chemiluminescent method (ECL, Amersham Biosciences). Quantitative analyses were performed using Bio-Rad GS imaging densitometer using QuantOne 4.6.2 software.

\section{Labeling of acute de novo protein translation}

$\mathrm{C}_{2} \mathrm{C}_{12}$ myotubes were grown in unlabeled media as described above. On day five post-differentiation, myotubes were exposed to either $250 \mathrm{mCi}{ }^{35}$ S-Methionine/ Cysteine or $1 \mu \mathrm{M}$ Prednisone and $250 \mathrm{mCi}{ }^{35}$ S-Methionine/Cysteine for 15 minutes. Each condition was carried out in triplicate cultures. Cytosolic proteins were isolated as described above. Total cytosolic protein $(200 \mu \mathrm{g})$ was buffer-exchanged (Tris-HCl, pH 7.4), concentrated, and then solubilized in isoelectric focusing rehydration buffer using a solution consisting of $7 \mathrm{~mol} / \mathrm{l}$ urea, $2 \mathrm{~mol} / \mathrm{l}$ thiourea, 1\% (wt/vol) ASB-14, 0.5\% (vol/vol) Triton X-100, 40 $\mathrm{mmol} / \mathrm{l}$ Tris base, $30 \mathrm{mmol} / \mathrm{l} \mathrm{DTT}$, and $0.5 \%$ (vol/vol) ampholytes 3-10. Samples were then loaded onto a 17$\mathrm{cm}, \mathrm{pH}$ 3-10 NL Immobilized pH Gradient strip and left under mineral oil overnight. IEF was conducted for a total of $100,000 \mathrm{Vh}$ (volt-hours) at $20^{\circ} \mathrm{C}$. Strips were incubated for $15 \mathrm{~min}$ in equilibration buffer ( $6 \mathrm{~mol} / \mathrm{l} \mathrm{urea,} \%$ [wt/ vol] SDS, $20 \%$ [vol/vol] glycerol, $0.15 \mathrm{~mol} / \mathrm{l}$ bis-Tris, and $0.1 \mathrm{~mol} / \mathrm{l} \mathrm{HCl}$ ) at $20^{\circ} \mathrm{C}$, first with $65 \mathrm{mmol} / \mathrm{l} \mathrm{DTT}$ and second with $243 \mathrm{mmol} / \mathrm{l}$ iodoacetamide. Strips were inserted into $12 \%$ SDS-PAGE gels and two-dimensional gels were run according to manufacturer instructions. After protein separation, the gel slabs were fixed in a solution of methanol:water:acetic acid (45:50:5, vol/vol/vol) and then in Amplify Fluorography (Amersham Biosciences) for 30 min. Gels were dried overnight under vacuum seal and stored at $-80^{\circ} \mathrm{C}$ for 25 hrs prior to film development.

\section{D-Gel quantification and analysis}

Gel images were analyzed by Ludesi. For spot identification, the same experimental design described above was used but without radioactivity. Non-radioactive gels followed the same procedure with the following exceptions. Cells were exposed to only prednisone for $15 \mathrm{~min}$. After 
second-dimension separation, gels were fixed $(45 \%$ $\mathrm{dH} 20 / 5 \%$ acetic acid/50\% methanol) followed by three washes for $5 \mathrm{~min}$ in deionized water. Staining was performed with Coomassie Blue followed by ample rinsing with deionized water until the desired contrast was obtained.

Spots were excised and transferred to a microcentrifuge tube containing $100 \mu \mathrm{l}$ of deionized water. Tryptic digestion was performed as described previously [46] and peptides were extracted and then dried by vacuum centrifugation. Dried peptides were subsequently dissolved in $10 \mu \mathrm{l}$ of $0.1 \%$ trifluoroacetic acid and desalted using $\mathrm{C}_{18}$ ZipTip micropipette tips following the manufacturer's instructions. Aliquots of peptide solutions were spotted on the matrix-assisted laser desorption/ionization (MALDI) plate. Mass spectrometry (MS) and tandem mass spectrometry (MS/MS) analyses were performed on a $4700 \mathrm{ABI}$ time-of-flight (TOF)-TOF mass spectrometer equipped with a Nd:YAG $200 \mathrm{~Hz}$ laser. The instrument was operated with delayed extraction in reflectron positive ion mode. A mixture of standard peptides was used to externally calibrate the instrument. Protein identification was carried out using GPS explorer v3.6 and searched against the IPI database v3.22. Both MS and MS/MS data were used for protein identification. In-gel digestion was performed as described above.

\section{Abbreviations}

ANXA2: Annexin A2; EEF1A1: elongation factor 1 alpha 1; GAIT: Gamma interferon activated inhibitor of Ceruloplasmin mRNA translation; GLRX3: glutaredoxin-3; HNRPK: ribonucleoprotein hnRNP K; IPA: Ingenuity Pathway Analysis; mRNA: messenger ribonucleic acid; NESG1: nasopharyngeal epithelium specific protein 1; NF: normalization factor; PA2G4: proliferation-associated 2G4; PKC: protein kinase C; RFC1: replication factor C subunit 1; SILAC: stable isotope labeling of amino acids; TOP: terminal oligopyrimidine; UTR: untranslated region; YBX1: Y-Box binding protein 1

\section{Competing interests}

The authors declare that they have no competing interests.

\section{Authors' contributions}

ER carried out all proteomic and molecular studies and drafted the majority of the manuscript. HGD helped performed statistical analysis on the proteomic quantitation data. EH made substantial contributions to the study conception and design and critically revised the manuscript for intellectual content. YH contributed to study conception and design, data analysis and interpretation. All authors have read and approved the final manuscript.

\section{Additional material}

\section{Additional file 1}

Protein identifications across time points of prednisone treated myotubes. The number of overlapping proteins between the time points for the cytosol and nuclear fractions is shown.

Click here for file

[http://www.biomedcentral.com/content/supplementary/14775956-7-26-S1.doc]

\section{Additional file 2}

Significantly altered proteins in response to prednisone. List of cytosolic and nuclear proteins significantly altered in response to prednisone. This list was included for network analysis using Ingenuity Analysis Pathway. Click here for file

[http://www.biomedcentral.com/content/supplementary/14775956-7-26-S2.xls]

\section{Acknowledgements}

Research supported by the Wellstone Muscular Dystrophy Center (IU54HD053 I77; http://www.wellstone-dc.org), the U.S. Department of Defense (W8IXWH-05-0334, W8IXWH-04-0I-008I), and a grant from the NIH National Center for Medical Rehabilitation Research

(5R24HD050846; http://www.ncmrr.org).

\section{References}

I. Larj MJ, Bleecker ER: Therapeutic responses in asthma and COPD. Corticosteroids. Chest 2004, I 26(2 Suppl): I38S-I49S.

2. Herrlich P: Cross-talk between glucocorticoid receptor and AP-I. Oncogene 200I, 20(19):2465-75.

3. Coghlan MJ, Elmore SW, Kym PR, Kort ME: The pursuit of differentiated ligands for the glucocorticoid receptor. Curr Top Med Chem 2003, 3(14):1617-35.

4. Gerritsen ME, Schwarz SM, Medow MS: Glucocorticoid-mediated alterations in fluidity of rabbit cardiac muscle microvessel endothelial cell membranes: influences on eicosanoid release. Biochim Biophys Acta 199I, 1065(I):63-8.

5. Kiss C, Balázs M, Kéri-Fülöp I: Dexamethasone decreases membrane fluidity of leukemia cells. Leuk Res 1990, I4(3):22I-5.

6. Dudeja PK, Dahiya R, Brown MD, Brasitus TA: Dexamethasone influences the lipid fluidity, lipid composition and glycosphingolipid glycosyltransferase activities of rat proximal-smallintestinal Golgi membranes. Biochem J 1 988, 253(2):40I-8.

7. Park $\mathrm{S}$, Taub M, Han H: Regulation of phosphate uptake in primary cultured rabbit renal proximal tubule cells by glucocorticoids: evidence for nongenomic as well as genomic mechanisms. Endocrinology 200I, I 42(2):7I0-20.

8. Solito E, Mulla A, Morris JF, Christian HC, Flower RJ, Buckingham JC: Dexamethasone induces rapid serine-phosphorylation and membrane translocation of annexin $I$ in a human folliculostellate cell line via a novel nongenomic mechanism involving the glucocorticoid receptor, protein kinase C, phosphatidylinositol 3-kinase, and mitogen-activated protein kinase. Endocrinology 2003, I44(4): I 164-74.

9. ten Hove W, Houben LA, Raaijmakers JA, Koenderman L, Bracke M: Rapid selective priming of FcalphaR on eosinophils by corticosteroids. JImmunol 2006, 177(9):6108-14.

10. Qiu J, Wang P, Jing Q, Zhang W, Li X, Zhong Y, Sun G, Pei G, Chen $Y$ : Rapid activation of ERKI/2 mitogen-activated protein kinase by corticosterone in PCI 2 cells. Biochem Biophys Res Commun 200I, 287(4): 1017-24.

II. Uz T, Dwivedi Y, Savani PD, Impagnatiello F, Pandey G, Manev H: Glucocorticoids stimulate inflammatory 5-lipoxygenase gene expression and protein translocation in the brain. J Neurochem 1999, 73(2):693-9. 
12. Dezitter X, Hammoudi F, Belverge N, Deloulme JC, Drobecq H, Masselot B, Formstecher P, Mendy D, Idziorek T: Proteomics unveil corticoid-induced SIO0AII shuttling in keratinocyte differentiation. Biochem Biophys Res Commun 2007, 360(3):627-32.

13. Almon RR, DuBois DC, Yao Z, Hoffman EP, Ghimbovschi S, Jusko WJ: Microarray analysis of the temporal response of skeletal muscle to methylprednisolone: comparative analysis of two dosing regimens. Physiol Genomics 2007, 30(3):282-99.

14. Giuliano KA, Taylor DL: Formation, transport, contraction, and disassembly of stress fibers in flbroblasts. Cell Motil Cytoskeleton 1990, 16:14-21.

15. Hahn KM, Waggoner AS, Taylor DL: A calcium-sensitive fluorescent analog of calmodulin based on a novel calmodulin-binding lluorophore. J Biol Chem 1990, 265:20335-45.

16. Giuliano KA, Kolega J, DeBiasio RL, Taylor DL: Myosin II phosphorylation and the dynamics of stress fibers in serum-deprived and stimulated fibroblasts. Mol Biol Chem 1992, 3:1037- 1048.

17. Miyawaki A, Llopis J, Heim R, McCaffery JM, Adams JA, Ikura M, Tsien RY: Fluorescent indicators for $\mathrm{Ca}+$ based on green fluorescent proteins and calmodulin. Nature 1997, 388(6645):882-7.

18. Grønborg M, Kristiansen TZ, Iwahori A, Chang R, Reddy R, Sato N, Molina H, Jensen ON, Hruban RH, Goggins MG, Maitra A, Pandey A: Biomarker discovery from pancreatic cancer secretome using a differential proteomic approach. Mol Cell Proteomics 2006, 5(I):|57-7|.

19. An E, Lu X, Flippin J, Devaney JM, Halligan B, Hoffman EP, Strunnikova $\mathrm{N}$, Csaky K, Hathout Y: Secreted proteome profiling in human RPE cell cultures derived from donors with age related macular degeneration and age matched healthy donors. J Proteome Res 2006, 5(10):2599-6I0.

20. Doherty MK, Whitehead C, McCormack H, Gaskell SJ, Beynon RJ: Proteome dynamics in complex organisms: using stable isotopes to monitor individual protein turnover rates. Proteomics 2005, 5(2):522-33

21. Dobreva I, Fielding A, Foster LJ, Dedhar S: Mapping the IntegrinLinked Kinase Interactome Using SILAC. J Proteome Res 2008 7(4): 1740- 1749.

22. Gruhler A, Olsen JV, Mohammed S, Mortensen P, Faergeman NJ, Mann M, Jensen ON: Quantitative phosphoproteomics applied to the yeast pheromone signaling pathway. Mol Cell Proteomics 2005, 4(3):310-27.

23. Ramsby ML, Makowski GS: Differential Detergent Fractionation of Eukaryotic Cells: Analysis by Two-Dimensional Gel Electrophoresis. In 2-D Proteome Analysis Protocols (Methods in Molecular Biology) Edited by: Link RA. Totowa, NJ: Humana Press; 1999:53-64.

24. Loreni F, Thomas G, Amaldi F: Transcription inhibitors stimulate translation of 5' TOP mRNAs through activation of S6 kinase and the mTOR/FRAP signalling pathway. Eur J Biochem 2000, 267(22):6594-60I.

25. Mintz M, Vanderver A, Brown KJ, Lin J, Wang Z, Kaneski C, Raphael Schiffmann R, Nagaraju K, Hoffman EP, Hathout Y: Time Series Proteome Profiling To Study Endoplasmic Reticulum Stress Response. J Proteome Res 2008, 7(6):2435-44.

26. Romijn EP, Christis C, Wieffer M, Gouw JW, Fullaondo A, Sluijs P van der, Braakman I, Heck AJ: Expression clustering reveals detailed co-expression patterns of functionally related proteins during B cell differentiation: a proteomic study using a combination of one-dimensional gel electrophoresis, LC-MS/MS, and stable isotope labeling by amino acids in cell culture (SILAC). Mol Cell Proteomics 2005, 4(9): I297-3।0.

27. Koukouritaki SB, Margioris AN, Gravanis A, Hartig R, Stournaras C: Dexamethasone induces rapid actin assembly in human endometrial cells without affecting its synthesis. J Cell Biochem 1997, 65(4):492-500.

28. Koukouritaki SB, Theodoropoulos PA, Margioris AN, Gravanis A Stournaras C: Dexamethasone alters rapidly actin polymerization dynamics in human endometrial cells: evidence for nongenomic actions involving cAMP turnover. J Cell Biochem 1996, 62(2):25I-6I.

29. Qiu J, Wang CG, Huang XY, Chen YZ: Nongenomic mechanism of glucocorticoid inhibition of bradykinin-induced calcium influx in PCI 2 cells: possible involvement of protein kinase C. Life Sci 2003, 72(22):2533-42.

30. Qi AQ, Qiu J, Xiao L, Chen YZ: Rapid activation of JNK and p38 by glucocorticoids in primary cultured hippocampal cells. Neurosci Res 2005, 80(4):510-7.
31. Billaudel B, Mathias PC, Sutter BC, Malaisse WJ: Inhibition by corticosterone of calcium inflow and insulin release in rat pancreatic islets. J Endocrinol 1984, I 00(2):227-33.

32. Witte S, Villalba M, Bi K, Liu Y, Isakov N, Altman A: Inhibition of the c-Jun N-terminal kinase/AP-I and NF-kappaB pathways by PICOT, a novel protein kinase C-interacting protein with a thioredoxin homology domain. J Biol Chem 2000, 275(3): 1902-9.

33. Samarel AM: PICOT: a multidomain scaffolding inhibitor of hypertrophic signal transduction. Circ Res 2008, 102(6):625-7.

34. Li Y, Martin LD, Spizz G, Adler KB: MARCKS protein is a key molecule regulating mucin secretion by human airway epithelial cells in vitro. Biol Chem 200I, 276(44):40982-90.

35. Disatnik MH, Boutet SC, Lee $\mathrm{CH}$, Mochly-Rosen D, Rando TA: Sequential activation of individual PKC isozymes in integrinmediated muscle cell spreading: a role for MARCKS in an integrin signaling pathway. J Cell Sci 2002, I I5(Pt I0):215I-63.

36. Liu J, Vishwanatha JK: Regulation of nucleo-cytoplasmic shuttling of human annexin A2: a proposed mechanism. Mol Cell Biochem 2007, 303(I-2):2II-20.

37. Liu J, Rothermund CA, Ayala-Sanmartin J, Vishwanatha JK: Nuclear annexin II negatively regulates growth of LNCaP cells and substitution of ser II and 25 to glu prevents nucleo-cytoplasmic shuttling of annexin II. BMC Biochem 2003, 4:10.

38. te Pas MF, de Jong PR, Verburg FJ: Glucocorticoid inhibition of $\mathrm{C} 2 \mathrm{Cl} 2$ proliferation rate and differentiation capacity in relation to mRNA levels of the MRF gene family. Mol Biol Rep 2000, 27(2):87-98.

39. Camacho-Vanegas $O$, Weighardt F, Ghigna C, Amaldi F, Riva S, Biamonti G: Growth-dependent and growth-independent translation of messengers for heterogeneous nuclear ribonucleoproteins. Nucleic Acids Res 1997, 25(19):3950-4

40. Davuluri RV, Suzuki Y, Sugano S, Zhang MQ: CART classification of human 5' UTR sequences. Genome Res 2000, I0(II):1807-16.

4I. Kleene KC, Distel RJ, Hecht NB: Translational regulation and deadenylation of a protamine mRNA during spermiogenesis in the mouse. Dev Biol 1984, 105(1):71-9.

42. Vedeler A, Hollas $H$ : Annexin II is associated with mRNAs which may constitute a distinct subpopulation. Biochem J 2000, 348:565-72.

43. Filipenko NR, MacLeod T], Yoon CS, Waisman DM: Annexin A2 is a novel RNA-binding protein. J Biol Chem 2004, 279(10):8723-31.

44. Sampath P, Mazumder B, Seshadri V, Fox PL: Transcript-selective translational silencing by gamma interferon is directed by a novel structural element in the ceruloplasmin mRNA 3 untranslated region. Mol Cell Biol 2003, 23(5):1509-19.

45. Hathout Y, Flippin J, Fan C, Liu P, Csaky K: Metabolic labeling of human primary retinal pigment epithelial cells for accurate comparative proteomics. J Proteome Res 2005, 4(2):620-7.

46. Jensen ON, Wilm M, Shevchenko A, Mann M: Sample preparation methods for mass spectrometric peptide mapping directly from 2-DE gels. Methods Mol Biol 1999, I I 2:5 I3-3.

Publish with Biomed Central and every scientist can read your work free of charge

"BioMed Central will be the most significant development for disseminating the results of biomedical research in our lifetime. "

Sir Paul Nurse, Cancer Research UK

Your research papers will be:

- available free of charge to the entire biomedical community

- peer reviewed and published immediately upon acceptance

- cited in PubMed and archived on PubMed Central

- yours - you keep the copyright 